\title{
(6) OPEN ACCESS \\ Interventions to increase the reporting of occupational diseases by physicians: a Cochrane systematic review
}

\author{
Stefania Curti, ${ }_{1}^{1}$ Riitta Sauni, ${ }^{2}$ Dick Spreeuwers, ${ }^{3}$ Antoon De Schryver, ${ }^{4}$ \\ Madeleine Valenty, ${ }^{5}$ Stéphanie Rivière, ${ }^{5}$ Stefano Mattioli ${ }^{1}$
}

${ }^{1}$ Department of Medical and Surgical Sciences, University of Bologna, Bologna, Italy

${ }^{2}$ Finnish Institute of

Occupational Health, Tampere, Finland

${ }^{3}$ Free University Medical Centre, Amsterdam, The Netherlands

${ }^{4}$ Epidemiology and Social Medicine, University of Antwerp, Antwerpen, Belgium ${ }^{5}$ Département Santé Travail, Institut de Veille Sanitaire, Saint Maurice, France

Correspondence to Dr Stefania Curti, Unità Operativa di Medicina del Lavoro, Policlinico S OrsolaMalpighi, via Pelagio Palagi 9 Bologna I-40138, Italy; stefania.curti@unibo.it

Received 24 July 2015 Revised 11 January 2016 Accepted 9 February 2016 Published Online First 2 March 2016
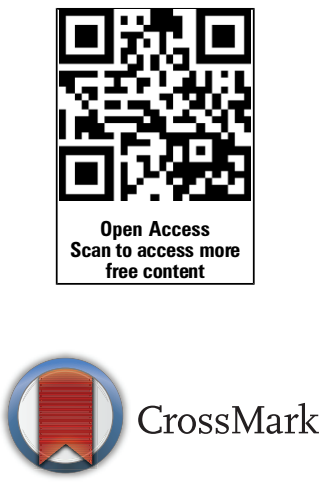

To cite: Curti $S$, Sauni $R$, Spreeuwers D, et al. Occup Environ Med 2016;73: 353-354.

\section{INTRODUCTION}

Under-reporting of occupational diseases is an important issue in many countries. Timely and complete reporting is fundamental to a successful physician-based public health surveillance system and to plan intervention programmes and allocation of resources.

For physicians, the main reasons for underreporting consist of lack of awareness regarding reporting requirements, time and effort involved in reporting and lack of benefit from reporting.

There are no systematic reviews of the effects of interventions for increasing the reporting (or reducing the under-reporting) of occupational diseases. Therefore, we conducted a Cochrane systematic review to evaluate the effectiveness of interventions aimed at increasing the reporting of occupational diseases by physicians. ${ }^{1}$

\section{METHODS}

We searched the Cochrane Occupational Safety and Health Group Specialised Register, the Cochrane Central Register of Controlled Trials (CENTRAL), MEDLINE (PubMed), EMBASE, OSH UPDATE, Database of Abstracts of Reviews of Effects (DARE), Open-SIGLE and Health Evidence, up to January 2015.

We intended to include randomised controlled trials (RCTs), cluster-RCTs, controlled before-after (CBA) studies and interrupted time series (ITS), on the effects of increasing the reporting of occupational diseases by physicians, but we only identified RCTs and CBA studies.

Outcome measures were the reporting of occupational diseases measured either as the number of physicians reporting or as the rate of reporting occupational diseases.

Two authors independently assessed study eligibility and risk of bias, and extracted data. The results of similar studies were combined in a meta-analysis. We assessed the overall quality of evidence for each combination of intervention and outcome, using the GRADE approach.

\section{RESULTS}

We included seven RCTs and five CBA studies in our review. Of the seven RCTs, five were reported in one article illustrating five intervention arms compared to one control each. The other two RCTs were described in a second article consisting of two intervention arms compared to the same control group.
Seven studies were conducted in the Netherlands, four studies in the USA and one had been performed in South Africa. The interventions were focused on occupational physicians in seven studies and other physicians in five studies.

Six studies evaluated the effectiveness of educational materials alone, one study evaluated educational meetings, four studies evaluated a combination of the two and one study evaluated a multifaceted educational campaign for increasing the reporting of occupational diseases by physicians. Ten studies compared active interventions to no intervention, whereas the comparison group of two other studies was a less intensive intervention, which consisted of a message explaining the benefits of reporting. All the included studies were judged to have a high risk of bias.

There was moderate-quality evidence from two studies that the use of a personally addressed electronic newsletter describing the pros and cons of reporting occupational diseases did not increase the number of physicians reporting occupational diseases compared to no intervention, with a risk ratio of 1.11 (95\% CI 0.74 to 1.67 ). We also found moderate-quality evidence from two studies that sending a reminder message of a legal obligation to report increased the number of physicians reporting occupational diseases when compared to a reminder message about the benefits of reporting (risk ratio of $1.32,95 \%$ CI 1.05 to 1.66 ; figure 1). Specifically, this intervention consisted of a letter to the physician emphasising the legal requirement to report (plus the benefits of reporting, in one of the two studies), an excerpt of public health law mandating the reporting, a one-page flyer explaining that public health law requires physicians to report current and future patients by completing and returning the accompanying form, a brochure describing how to report and a listing of reportable conditions, and a reporting form with patient information from previous hospital records regarding a case with reportable condition that had not been reported by that physician.

There was low-quality evidence from four studies that the provision of educational materials did not increase the rate of reporting when compared to no intervention.

Likewise, we found that the use of both, educational materials and meetings, did not considerably increase the number of physicians reporting occupational diseases nor the rate of reporting. Similar findings were found for the use of educational meetings alone. The use of an educational 


\begin{tabular}{|c|c|c|c|c|c|c|c|c|c|}
\hline Study or Subgroup & \multicolumn{2}{|c|}{ Intervention } & \multicolumn{2}{|c|}{ Control } & \multicolumn{2}{|r|}{ Risk Ratio } & \multicolumn{2}{|c|}{$\begin{array}{c}\text { Risk Ratio } \\
\text { M-H, Fixed, } 95 \% \mathrm{Cl} \\
\end{array}$} & \\
\hline \multicolumn{10}{|c|}{ 3.1.1 Legal obligation to report reminder message vs. benefits of reporting message } \\
\hline $\begin{array}{l}\text { Brissette } 2006 \mathrm{a} \\
\text { Subtotal }(95 \% \mathrm{Cl})\end{array}$ & $5 ?$ & $\begin{array}{l}105 \\
105\end{array}$ & 27 & $\begin{array}{l}62 \\
62\end{array}$ & $\begin{array}{l}48.7 \% \\
48.7 \%\end{array}$ & $\begin{array}{l}1.25[0.89,1.74] \\
\mathbf{1 . 2 5}[\mathbf{0 . 8 9}, \mathbf{1 . 7 4}]\end{array}$ & & & \\
\hline $\begin{array}{l}\text { Total events } \\
\text { Heterogeneity: Not } \\
\text { Test for overall effec }\end{array}$ & $\begin{array}{c}57 \\
\text { plicable } \\
Z=1.30\end{array}$ & $=0.20$ & 27 & & & & & & \\
\hline \multicolumn{10}{|c|}{ 3.1.2 Legal obligation to report plus benefits of reporting reminder message vs. benefits of reporting message } \\
\hline $\begin{array}{l}\text { Brissette } 2006 \mathrm{~b} \\
\text { Subtotal }(95 \% \mathrm{Cl})\end{array}$ & 73 & $\begin{array}{l}121 \\
\mathbf{1 2 1}\end{array}$ & 27 & $\begin{array}{l}62 \\
62\end{array}$ & $\begin{array}{l}51.3 \% \\
51.3 \%\end{array}$ & $\begin{array}{l}1.39[1.01,1.90] \\
\mathbf{1 . 3 9}[\mathbf{1 . 0 1}, \mathbf{1 . 9 0}]\end{array}$ & & & \\
\hline \multicolumn{10}{|c|}{$\begin{array}{l}\text { Heterogeneity: Not applicable } \\
\text { Test for overall effect: } Z=2.01 \quad(P=0.04)\end{array}$} \\
\hline Total $(95 \% \mathrm{Cl})$ & & 226 & & 124 & $100.0 \%$ & $1.32[1.05,1.66]$ & & & \\
\hline Total events & 130 & & 54 & & & & & & \\
\hline $\begin{array}{l}\text { Heterogeneity: Chi } \\
\text { Test for overall effec } \\
\text { Test for subaroup di }\end{array}$ & $\begin{array}{l}0.20, \mathrm{df}= \\
Z=2.35( \\
\text { erences: }\end{array}$ & $\begin{array}{l}1(P=0 \\
=0.02 \\
h i^{2}=0 .\end{array}$ & $\begin{array}{l}65) ; l^{2}= \\
20 . \\
d f=1\end{array}$ & $(P=0$ & (.65). $F=0$ & & $\begin{array}{ll}0.7 & 0.85 \\
\text { Favours contro }\end{array}$ & $1 \frac{1.2}{1}$ & $\begin{array}{c}1.5 \\
\text { vention }\end{array}$ \\
\hline
\end{tabular}

Figure 1 Meta-analysis of the effects of educational materials versus less intensive intervention (outcome measure, number of physicians reporting occupational diseases). M-H: Mantel-Haenszel method for synthesising studies; Fixed: fixed-effect model; $95 \% \mathrm{Cl}$.

campaign appeared to increase the number of physicians reporting occupational diseases, although this was based on very lowquality evidence.

We did not find studies evaluating the effectiveness of internet-based interventions, simplification of procedures or techniques of reporting (eg, through online reporting), or the use of financial incentives. Moreover, no studies evaluating large-scale interventions, such as the introduction of new laws, existing or new disease-specific registries or surveillance systems, were found.

\section{DISCUSSION}

The included studies provided evidence ranging from very low to moderate quality showing that educational materials, educational meetings, or a combination of the two, did not considerably increase the reporting of occupational diseases. The use of a reminder message on the legal obligation to report seemed more effective than a simple message about the pros and cons of reporting occupational diseases. High-quality RCTs are needed to clarify the effectiveness of these interventions.

There was very low-quality evidence that the implementation of an educational campaign increased the number of physicians reporting occupational diseases compared to no intervention. The evaluation of these large-scale interventions should be performed by ITS study designs where the outcome is measured several times before and after the intervention.

The included studies had been conducted in three countries, only limiting the evaluation of the applicability of the results. The evidence from a very small number of countries would not directly apply to other countries, considering also differences in legislation between them. The type of participants involved in the review likely reflects the different needs, issues and approaches used to increase the reporting of occupational diseases in the different countries.

This review did not evaluate the effectiveness of interventions other than education, such as the use of financial incentives, which could be an important form of motivation for changing physicians' behaviour. Such small-scale interventions could be investigated using larger RCTs, while the evaluation of large-scale interventions such as legislation should use an ITS design.

Acknowledgements This review was conducted under the auspices of the Cochrane Occupational Safety and Health Review Group. The authors thank Professor Raymond Agius and the COST-Modernet group for their support.

Funding Bursary for the best 2012 proposal awarded by the Cochrane Occupational Safety and Health Review Group. The COST Action IS1002 Modernet covered all the costs of arranging meetings between the authors.

Competing interests None declared.

Provenance and peer review Not commissioned; internally peer reviewed.

Open Access This is an Open Access article distributed in accordance with the Creative Commons Attribution Non Commercial (CC BY-NC 4.0) license, which permits others to distribute, remix, adapt, build upon this work non-commercially, and license their derivative works on different terms, provided the original work is properly cited and the use is non-commercial. See: http://creativecommons.org/ licenses/by-nc/4.0/

\section{REFERENCE}

1 Curti S, Sauni R, Spreeuwers D, et al. Interventions to increase the reporting of occupational diseases by physicians. Cochrane Database Syst Rev 2015;3:CD010305. 